\title{
Bilateral globus pallidus lesions
}

\author{
Maria A Parekh
}

Department of Neurology, Baylor College of Medicine, Houston, Texas, USA

\section{Correspondence to}

Dr Maria A Parekh;

m.afridi.parekh@gmail.com

Accepted 19 January 2021

\section{DESCRIPTION}

This report highlights a striking image of incidentally discovered selective symmetrical chronic bilateral globus pallidus infarction in a 28 -year-old man as a result of cocaine use. He presented to the emergency department for evaluation of acute onset of left arm weakness, most prominent distally and in the extensor compartment, with associated areflexia. He did not have any hyperkinetic or hypokinetic movement disorders. He underwent MRI of the brain and cervical spine which did not reveal acute stroke or demyelinating disease. Chronic bilateral globus pallidus infarctions were seen and reported (figure 1), and in the absence of other vascular risk factors, this was attributed to his long-standing history of cocaine use disorder. Given that the suspicion for brachial plexopathy was high, he was started on high-dose intravenous steroids with improvement in symptoms and an MRI of the brachial plexus was obtained.

The globi pallidi are paired structures that are a part of the basal ganglia, which also include the caudate, putamen, substantia nigra and subthalamic nuclei. ${ }^{1}$ Radiologically, the basal ganglia are normally isodense or isointense to the cortex, but the globi pallidi with their higher myelin content compared with the putamen, usually appear slightly more hypointense on the T2/FLAIR (fluid-attenuated inversion recovery), GRE (gradient echo) and SWI (susceptibility-weighted) sequences. In this case (figure 1), the globi pallidi appear hypointense with a hyperintense rim on FLAIR, hypointense on SWI, with negative DWI (diffusionweighted imaging) and ADC (apparent diffusion coefficient), consistent with a chronic haemorrhagic infarct.

The function of the basal ganglia is to primarily regulate extrapyramidal motor activity, but they are also involved in memory, emotion and other cognitive functions. ${ }^{2}$ Lesions affecting the globus pallidus selectively have been associated with behavioural and cognitive disorders. The neurotransmissive function of the basal ganglia is heavily dependent on their high metabolic activity requiring a rich anastomotic blood supply, explaining their vulnerability to various conditions in which blood or oxygen or energy levels are

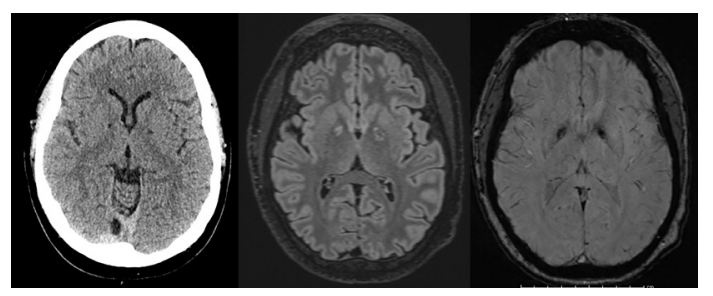

Figure 1 Noncontrast CT head and MRI (FLAIR and SWI sequences) showing symmetrical selective chronic bilateral globi pallidi lesions.

\section{Learning points}

- The globus pallidi are rich in mitochondria, vascular supply, neurotransmitters and chemical content compared with other areas in the brain, and their high metabolic activity and increased utilisation of glucose and oxygen make them vulnerable to metabolic abnormalities and many systemic or generalised disease processes.

- Differential diagnostic considerations for isolated bilateral pallidal lesions include carbon monoxide poisoning, methylmalonic acidemia, disulfiram toxicity and cocaine use disorder.

diminished. ${ }^{3}$ Bilateral infarcts confined to the globus pallidus are unusual and occur in conjunction with only a few disorders with differential diagnostic considerations including carbon monoxide poisoning, methylmalonic acidemia, disulfiram toxicity, ${ }^{4}$ recently reported COVID-19 hypoxemia ${ }^{5}$ and cocaine use disorder. Identification of aetiology is based on history taking and laboratory testing. The spectrum of neuropathological alterations seen with cocaine consumption is broad, consisting of vascular complications such as stroke, subarachnoid and intracerebral haemorrhages and cerebral ischaemia.

Twitter Maria A Parekh @MariaParekh

Contributors MAP independently conceptualised and designed the study, acquired and interpreted the data, drafted and revised the article for important intellectual content. MAP takes full responsibility for the data, interpretation and the conduct of the research; has full access to all of the data; and has the right to publish any and all data separate and apart from any sponsor.

Funding The authors have not declared a specific grant for this research from any funding agency in the public, commercial or not-for-profit sectors.

Disclaimer All patient identifiable data have been removed from the article and the figure(s).

Competing interests None declared.

Patient consent for publication Obtained.

Provenance and peer review Not commissioned; externally peer reviewed.

\section{ORCID iD}

Maria A Parekh http://orcid.org/0000-0003-0465-8400

\section{REFERENCES}

1 Brazis PW, Masdeu JC, Biller J. Localization in clinical neurology. $5^{\text {th }}$ edn. Philadelphia: Lippincott Williams \& Wilkins, 2007.

2 Milton WJ, Atlas SW, Lexa FJ, et al. Deep gray matter hypointensity patterns with aging in healthy adults: MR imaging at $1.5 \mathrm{~T}$. Radiology 1991;181:715-9.

3 Finelli PF, DiMario FJ. Diagnostic approach in patients with symmetric imaging lesions of the deep gray nuclei. Neurologist 2003;9:250-61.

4 Mesiwala AH, Loeser JD. Bilateral globus pallidus infarction secondary to disulfiram ingestion. Pediatr Neurosurg 2001;34:224.

5 Kulick-Soper CV, McKee JL, Wolf RL, et al. Pearls \& Oy-sters: Bilateral globus pallidus lesions in a patient with COVID-19. Neurology 2020;95:454-7. 
Copyright 2021 BMJ Publishing Group. All rights reserved. For permission to reuse any of this content visit https://www.bmj.com/company/products-services/rights-and-licensing/permissions/

BMJ Case Report Fellows may re-use this article for personal use and teaching without any further permission.

Become a Fellow of BMJ Case Reports today and you can:

- Submit as many cases as you like

- Enjoy fast sympathetic peer review and rapid publication of accepted articles

Access all the published articles

Re-use any of the published material for personal use and teaching without further permission

Customer Service

If you have any further queries about your subscription, please contact our customer services team on +44 (0) 2071111105 or via email at support@bmj.com.

Visit casereports.bmj.com for more articles like this and to become a Fellow 